\title{
Mathematical Methods of Calculating the Reliability of Standby Systems with Renewal
}

\author{
Mokaddis G.S ${ }^{1}$ \& Hana'a Alhajeri ${ }^{2}$ \\ ${ }^{1}$ Faculty of science Department of Mathematics, Ain Shams University, Cairo, Egypt \\ ${ }^{2}$ Faculty of science Department of statistics, Kuwait University \\ Correspondence: Mokaddis G.S, Faculty of science Department of Mathematics, Ain Shams University, Cairo, \\ Egypt.
}

Received: February 1, 2019

Accepted: March 19, 2020

Online Published: March 20, 2020

doi:10.5539/mas.v14n4p34

URL: https://doi.org/10.5539/mas.v14n4p34

\begin{abstract}
The mathematical methods of calculating the reliability of renewable systems based on the use of Markov's random processes (RYABININ, L., 1976). The simplest case of calculating the reliability of a renewable system without redundant units has been given. The availability and the reliability of a lightly loaded standby redundant system have been considered. Explicit results are obtained in the case of two main units and two standby redundant units.
\end{abstract}

Keywords: markov Random process, reliability, availability, loaded standby, lightly loaded standby

\section{The Reliability of a Non-Redundant System with Renewal}

Complete and partial failures repeatedly occur in any system during the time of its operation. Each time a failure is remedied the capability of the system is restored and the system continues to serve its purpose, the time of operation of a system between two failures forms only an insignificant part of its service. Life is determined by the total duration of operation until the system is entirely worn out (when it is acknowledged as fully unsuitable for further operation).

Maintenance is eliminating the failure by repair; the repairs of the failed units are carried out by a group of servicing elements.

As in the case of redundancy, renewal is a means of increasing the reliability of systems intended for prolonged use. Today, many systems rank precisely among the category of renewable systems and it is therefore necessary to know the methods of calculating the reliability of a system with renewal.

Let us consider a renewable non-redundant system intended for prolonged functioning and which can be either in an operative or inoperative state at each specific moment of time $t$ of its period of operation, $t_{0}$, depending on the tasks imposed on it. The loss of capability, i.e., failure of the system, may occur in the operative state of the system (when it is functioning according to its purpose) and in the inoperative state (when the system may remain idle at a given moment). In the latter case failure may be eliminated before need arises of starting it again, or everything left as it is (because repairs require more time than may be permitted by the circumstances).

The problem is to determine the probability $\mathrm{B}(t)$ of finding the system in failure-free operation at the moment $t$ and the probability $R(T)$ of unfailing operation of this system during the time $T$ beginning from the moment $t$. The first probability describes the reliability of the system from the point of view of its preparedness for immediate action at any moment of time $t$, and the second probability describes the reliability of the system from the standpoint of its unfailing functioning in the course of the required interval of time $T$.

We solve this problem with the two essential assumptions:

(i) The life time of the system is a random variable obeying the exponential distribution with rate $\lambda=$ constant.

(ii) The repair time of the system is a random variable obeying exponential distribution with rate $\mu=$ constant.

Denote by $E$ the state of the system at any moment; $E$ equal to $E_{0}$ when the system is operative and equal to $E_{1}$ when the system is inoperative. Let $\mathrm{P}_{0}(\mathrm{t}), \mathrm{P}_{1}(\mathrm{t})$ be the probabilities that the system is in the operative and 
non-operative states at moment $t$ respectively.

Studying the system at the moment $\mathrm{t}$, and at the moment $\mathrm{t}+\Delta \mathrm{t}$, and letting $\Delta \mathrm{t} \rightarrow 0$ we easily obtain the following equations.

$$
\begin{gathered}
P_{o}^{\prime}(t)=-\lambda P_{0}(t)+\mu P 1(t), \\
P_{1}^{\prime}(t)=-\lambda P_{0}(t)+\mu P 1(t),
\end{gathered}
$$

with the initial conditions $\mathrm{P}_{0}(0)=1, \mathrm{P}_{1}(0)=0$ and satisfied requirement $\mathrm{P}_{0}(t)+\mathrm{P}_{1}(t)=1$. This system of linear non homogenous differential equations has the following solution:

$$
\begin{gathered}
\left.p_{0}(t)=\frac{\mu}{\lambda+\mu}\left[1+\frac{\lambda}{\mu} \exp \{-\lambda+\mu) t\right\}\right], \\
\left.p_{1}(t)=\frac{\mu}{\lambda+\mu}[1-\exp \{-\lambda+\mu) t\}\right],
\end{gathered}
$$

The value of $\mathrm{P}_{0}(\mathrm{t})$ is nothing but the probability of finding the system in good order at any arbitrary moment $\mathrm{t}$, i.e., the probability $\mathrm{B}(\mathrm{t})$ which we had to find:

$$
B(t)=P_{o}=\frac{1}{1+p}[1-\rho \exp \{-(\lambda+\mu) t\}],
$$

here:

$$
\rho=\frac{\lambda}{\mu}=\frac{\text { Mean repair time } T_{r}}{\text { Mean life time } T_{f}},
$$

is the fault coefficient. The dependence of the probability B $(t)$ on the value of the fault coefficient $\rho$ is shown in Figure 1.

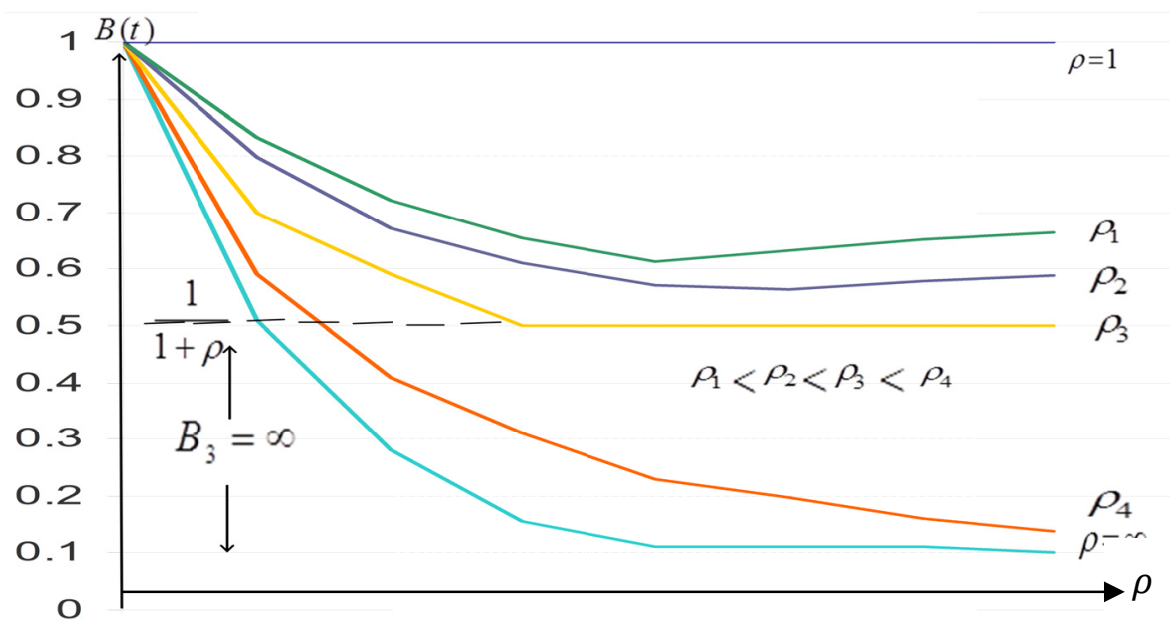

Figure 1. The reliability of the system decreases with higher $\rho$

Under the conditions of the problem in hand, the probability of an uninterrupted unfailing operation of a system during the time $\mathrm{T}$ starting with the moment $t$, can be easily found from the formula of the exponential law of reliability, namely

$$
R(T)=e^{-\lambda T}
$$

In this way, the probability that the system will be in order at the moment $t$ and liable to operate further faultlessly during the time $\mathrm{T}$ is equal to

$$
R(t, T)=B(t) R(T)=\frac{1}{1+\rho}\left[1+\rho e^{-(\lambda \mu) t}\right] e^{-\lambda T}
$$

if $t$ is large enough, then,

$$
R(\infty, T)=\frac{1}{1+\rho} e^{-\lambda T}
$$

It should be noted in conclusion that renewal as understood in this problem improves the reliability of the system only in the sense of increasing its availability. But the probability of the unfailing operations of the system is 
entirely determined by the intensity of failure $\lambda$. In the absence of renewal $(\mu=0)$, formula (1.6) is transformed into the expression.

$$
R(t, T)=e^{-\lambda(t+T)}
$$

The efficiency of renewal can be estimated from the quantitative aspect by the coefficient $\mathrm{K}_{\mathrm{e}}(\mathrm{t})$ which is equal to the ratio of the probabilities determined from formulas (1.6) and (1.8):

$$
K e(t)=\frac{1}{1+\rho}\left[e^{-\lambda t}+\rho e^{-\mu t}\right]
$$

or if $\mathrm{t}$ is large enough, then

$$
K e=\frac{1}{1+\rho} e^{-\lambda t}
$$

If $\mathrm{t}=0$, then

$$
K e=\frac{1}{1+\rho}
$$

As could "be expected this efficiency increases with a growth in the intensity of renewal $\mu$, the intensity of failures $\lambda$, and time $\mathrm{t}$.

\section{The Availability of Standby Redundant System with Renewal}

Let us consider a renewable reserved system consisting of $\mathrm{N}$ operating and $\mathrm{m}$ standby single-type units. This system functions as follows. The task is posed with the system performed by a group of $N$ units. When one of the units in this group fails it is instantaneously replaced by a redundant one and the faulty unit goes for renewal. The servicing system is composed of $L$ units. If all the servicing units are engaged, the faulty unit queues for renewal. The renewed unit is kept as a standby. In the general case, redundant units may also prove faulty. In this case they are also delivered to the servicing system for renewal. This system is known as the lightly loaded standby system with renewal.

Let us now describe the mathematical aspects of this system. The system fails when $m+1$ units have failed. Let us take it for granted that the system is in state $\mathrm{E}_{\mathrm{K}}$ when the number of the failed units is $K$. Obviously, the system is in good order in the states $E_{0}, E_{1}, E_{m}$. The state $E_{m+1}$ is the state of failure of the system; the states, $\mathrm{E}_{\mathrm{m}+2}, \mathrm{E}_{\mathrm{S}}(\mathrm{S}>\mathrm{N}+\mathrm{m})$ are regarded as impossible.

Let the life time of a main unit be distributed according to the exponential law with parameter $\lambda$, and that of a standby unit with parameter $r \lambda$, where the coefficient $r$ may range from 0 to 1 . Also, let the time needed to renew one unit by one servicing unit has an exponential distribution with parameter $\mu$. If the system is in a state $\mathrm{E}_{\mathrm{K}}$ when there are $\mathrm{N}$ operating units, and $\mathrm{k}$ failed units out of the $\mathrm{m}$ standby units, the intensity of failures among the operating and standby elements will be

$$
N \lambda+(m-K) r \lambda=n_{K} \lambda
$$

where:

$$
n_{K}=N+(m-K) r, N \leq n_{K} \leq N+m r .
$$

Let us denote the probability of finding the system in the state $E_{k}$ at any moment $t$ by $P_{K}(t)(t)$. We shall naturally be interested in the probabilities of all possible states $\mathrm{P}_{0}(t), \mathrm{P}_{1}(\mathrm{t}), \mathrm{P}_{\mathrm{m}=1}(\mathrm{t})$ in order to determine the system availability. According to the condition of the problem, the probabilities $\mathrm{P}_{\mathrm{m}+2}{ }^{(\mathrm{t})}=\ldots=\mathrm{P}_{\mathrm{s}}^{(\mathrm{t})}=0$.

We derive the difference differential equations governing the system. By connecting the probabilities at time $t+$ $\Delta$ with those at time $t$ and taking limits as

$\Delta t \rightarrow 0$, we have

$$
\begin{gathered}
P_{o}^{\prime}(t)=-n_{o} \lambda P_{o}(t)+\mu P_{1}(t) \\
P_{k}^{\prime}(t)=-\left(n_{k} \lambda+k \mu\right) P_{k}(t)+n_{k-1} \lambda P_{k-1}(t)+(k+1) \mu P_{k+1}(t) \\
P_{m}^{\prime}(t)=-\left(n_{m} \lambda+m \mu\right) P_{m}(t)+n_{m-1} \lambda P_{m-1}(t)+(m+1) \mu P_{m+1}(t) \\
P_{m+1}^{\prime}(t)=-(m+1) \mu P_{m+1}(t)+n_{m} \lambda P_{m}(t)
\end{gathered}
$$

This system can be solved by means of Laplace transforms, but a steady state solution is sufficient to find the availability. According to Markov's theorem [8],

$$
P_{k}^{\prime}(\infty)=0 \text { and } P_{K}(\infty)=P_{K}=a
$$

Constant. Then in the steady-state case, the system of equations can be written in the form 


$$
\begin{gathered}
\mu P_{1}=n_{o} \lambda P_{o,} \\
2 \mu P_{2}=\left(n_{1} \lambda+\mu\right) P_{1,}-n_{o} \lambda P_{o,} \\
k \mu P_{k}=\left[n_{k-1} \lambda+(k-1) \mu\right] P_{k-1}-n_{k-2} \lambda P_{k-2} \\
(m+1) \mu P_{m+1}=\left[n_{m} \lambda+m \mu\right] P_{m}-n_{m-1} \lambda P_{m-1}, \\
0=(m+1) \mu P_{m+1}-n_{m} \lambda P_{m}
\end{gathered}
$$

Solving the system (2.4) consecutively for $\mathrm{k}=1.2 \ldots, \mathrm{m}+1$, we find that

$$
P_{K}=\frac{1}{K !} \prod_{i=0}^{k-1} n_{i}\left(\frac{\lambda}{\mu}\right)^{k} P_{o}
$$

From the normalized conditio $\sum_{\mathrm{k}=\mathrm{o}}^{\mathrm{m}+1} \mathrm{p}_{\mathrm{k}}=1$, we get

$$
P_{o}=\left[1+\sum_{k=1}^{m+1} \frac{1}{k !} \prod_{i=o}^{k-1} n_{i}\left(\frac{\lambda}{\mu}\right)^{k}\right]^{-1}
$$

The availability as the probability of finding not more than $m$ units faulty at any moment are equal to

$$
B(\infty)=\sum_{k=o}^{m} p_{k}=\left\{\sum_{k=o}^{m} \frac{p k}{k !} \prod_{i=o}^{k-1} n_{i}\right\} /\left\{\sum_{k=o}^{m+1} \frac{p k}{k !} \prod_{i=o}^{k-1} n_{i}\right\}
$$

Here $n_{1}=1 \rho=\frac{\lambda}{\mu}$.

Explicit results for the case of two main units $(\mathrm{N}=2)$ and two standby units $(\mathrm{m}=2)$, in which, case $\lambda=0.1 \times 1 / \mathrm{h}$ $\mu=1 \times 1 / \mathrm{h}$ and $\rho=0.1$ are given below.

Let us consider some particular cases for the solution of this problem assuming the different natures of the standby (lightly loaded, loaded and nonleaded) and also the different kinds of repair (unlimited and limited). With the lightly loaded standby for $r=0.5$ from formula (2.1) we have $\mathrm{n}_{\mathrm{o}}=3, n_{1}=2.5$ and $n_{2}=2$ In the case of an unlimited renewal, the system availability can be found from formula (2.7):

$$
B(\infty)=\frac{1+n_{o} \rho+\frac{\rho^{2}}{2 !} n_{o} n_{1}}{1+n_{o} \rho+\frac{\rho^{2}}{2 !} n_{o} n_{1}+\frac{\rho^{3}}{3 !} n_{o} n_{1} n_{2}}=0.9981 .
$$

For the loaded standby $(\mathrm{r}=1)$ and with, the unlimited we have

$\left(\mathrm{L} \geq \mathrm{m}+1=3\right.$ ) we have $\mathrm{n}_{\mathrm{o}}=4, \mathrm{n}_{1}=3, \mathrm{n}_{2}=2$

$$
B_{1}(\infty)=\frac{1+4 \times 0.1+\frac{4 \times 3}{2} 0.01}{1+4 \times 0.1+\frac{4 \times 3}{2} 0.01+\frac{4 \times 3 \times 2}{3 \times 2} \times 0.001}=0.9973
$$

For the nonloaded standby $(r=0)$ and the renewal is unlimited $(\mathrm{L} \geq 3)$ we get $\mathrm{n}_{\mathrm{o}}=\mathrm{n}_{1}=\mathrm{n}_{2}=N=2=$ Constant, $\mathrm{B}_{2}(\infty)=0.9989$.

For the limited renewal $(\mathrm{L}=1)$, the coefficients are everywhere equal to unity when $\mu$ is in the system of equations (2.3). It can be shown that in this case when $r=1$.

$$
B(\infty)=\frac{\sum_{k=0}^{m} \frac{1}{(s-K) !} \rho^{k}}{\sum_{k=0}^{m+1} \frac{1}{(s-K) ! \rho^{k}}}
$$

where $S$ is the total number of single-type units functioning in the system. When $S>N+$ m some of the units are inoperative (being renewed or queueing for maintenance). Then

$$
B_{3}(\infty)=\frac{\frac{1}{4 !}+\frac{0.1}{3 !}+\frac{0.01}{2 !}}{\frac{1}{4 !}+\frac{0.1}{3 !}+\frac{0.01}{2 !}+\frac{0.001}{1 !}}=0.9690
$$

and where $r=0$

$$
\begin{gathered}
B(\infty)=\frac{1-(N p)^{m+1}}{1-(N p)^{m+2}} \\
B_{4}(\infty)=\frac{1-(2 \times 0.1)^{3}}{1-(2 \times 0.1)^{4}}=0.9935 .
\end{gathered}
$$

Let us illustrate these results in a tabulated form 
Table 1. System Availability Numbers

\begin{tabular}{ccc}
\hline Kind of repair & Loaded & Standby \\
& $\mathrm{B}_{1}(\infty)=0.0073$ & Non-loaded \\
\hline Unlimited & $\mathrm{B}_{3}(\infty)=0.9690$ & $\mathrm{~B}_{2}(\infty)==0.9989$ \\
Limited (with $\mathrm{L}=1)$ & $\mathrm{B}_{4}(\infty)==0.9935$
\end{tabular}

The table shows that the results of calculating the availability numbers of this system correctly describe the relationships between the values of $\mathrm{B}(\infty)$ for various cases of reserving and renewal

\section{The Reliability of a Lightly Loaded Standby Renewable System}

Let us take a system that satisfied the conditions indicated in the previous section and find the probability $\mathrm{R}(T)$ of unfailing operation of the system within the times interval $[0, T]$. The system passed into the state failure with the failure of the $(\mathrm{m}+\mathrm{l})$-th unit and the operating state with the renewal of the $\mathrm{N}$-th. unit.

The failure of the $(\mathrm{m}+1)$-th. unit may occur for the first time before the moment $T+\Delta T$ in the following two mutually exclusive cases:

(a) either the failure occurs before the moment $T$; this event has a probability $\mathrm{p}_{\mathrm{m}+1}(\mathrm{~T})$,

(b) or the $\mathrm{m}$-th failure occurs before this moment, and during the time $\Delta T$ one more, $(\mathrm{m}+1)$-th, failure occurs; this event has probability $\mathrm{p}_{\mathrm{m}}(\mathrm{T}) \mathrm{n}_{\mathrm{m}} \lambda \Delta T$.

so we have

$$
P_{m+1}(T+\Delta T)=P_{m+1}(T)+n_{m} \lambda \Delta T P_{m}(T)
$$

When $\Delta T \rightarrow 0$ we get in the limit

$$
P_{m+1}^{\prime}(T)=n_{m} \lambda P_{m}(T)
$$

In order to solve this equation it is necessary know the value of $P_{\mathrm{m}}(\mathrm{t})$ which is the probability of finding $\mathrm{m}$ units faulty at the moment $T$ not necessarily for the first time, But this value will provide the solution for the system of differential equations (2.3) if $\mathrm{m}$ is taken instead of $m+1$.

Having determined the probability $P_{\mathrm{m}+1}(T)$ this probability of unfailing operation of the system with a repairable standby can be evaluated from the formula.

$$
R(T)=1-P_{m+1}(T)
$$

Applying the Laplace transformation to the system of equations (2.3) and taking account of equation (3.2), we get

$$
\begin{gathered}
\left(z+n_{0} \lambda\right) P_{0}^{*}(z)-\mu P_{1}^{*}(z)=p_{0}(0) \\
-n_{0} \lambda P_{0}^{*}(z)+\left(z+n_{1} \lambda+\mu\right) P_{1}^{*}(z)-2 \mu P_{2}^{*}(z)=p_{1}(0) \\
-n_{k-1} \lambda P_{k-1}^{*}(z)+\left(z+n_{k} \lambda+k \mu\right) P_{k}^{*}(z)-(k+1) \mu P_{k+1}^{*}(z)=p_{k}(0) \\
-n_{m-2} \lambda P_{m-2}^{*}(z)+\left[z+n_{m} \lambda+(m-1) \mu\right] P_{m-1}^{*}(z)-m \mu P_{m}^{*}(z)=p_{m-1}(0) \\
-n_{m-1} \lambda P_{m-1}^{*}(z)+\left(z+n_{m} \lambda+m \mu\right) P_{m}^{*}(z)=P_{m}(0) \\
-n_{m} \lambda P_{m}^{*}(z)+z P_{m+1}^{*}(z)=P_{m+1}(0)
\end{gathered}
$$

where $P_{k}^{*}(z)$ is Laplace transform of the probability $P_{K}(t)$.

Let us solve this system with respect to $P_{m}^{*}+1(z)$ for the initial conditions.

$$
P_{k}(0)=1 ; P_{i}(0)=0(i=0,1 \ldots, m ; i \neq K)
$$

The sought-for solution is:

$$
P_{m+1}^{*(k)}(z)=\frac{\Delta^{(k)}(z)}{\Delta(z)}
$$

where $(\mathrm{k})$ is the index showing the numbers of faulty unite at the initial moment of time; $\Delta(\mathrm{Z})$ is the determinant of system (3.4) and is equal to 


$$
\begin{gathered}
\Delta(z) \\
=\left|\begin{array}{cccccccc}
z+n_{o} \lambda & -\mu & 0 & \ldots & 0 & 0 & 0 & 0 \\
-n_{o} \lambda & z+n_{1} \lambda+\mu & -2 \mu & \ldots & 0 & 0 & 0 & 0 \\
0 & -n_{1} \lambda & z+n_{2} \lambda+2 \mu & \ldots & 0 & 0 & 0 & 0 \\
\ldots & \ldots & \ldots & \ldots & \ldots & \ldots & \ldots & \ldots \\
0 & 0 & 0 & \ldots & -n_{m-2} \lambda & z+n_{m-1} \lambda(m-1) \mu & -m \mu & 0 \\
0 & 0 & 0 & \ldots & 0 & -n_{m-1} & z+-n_{m} \lambda+m \mu & 0 \\
0 & 0 & 0 & \ldots & 0 & 0 & -n_{m} \lambda & z
\end{array}\right|
\end{gathered}
$$

and $\Delta^{(\mathrm{k})}(z)$ is the determinant of system (3.4) in which the column of the coefficients of $P_{m+1}^{*}(z)$ is replaced by the column of free terms for the accepted initial conditions (3.5);

$$
\begin{aligned}
& \Delta^{(k)}(z)
\end{aligned}
$$

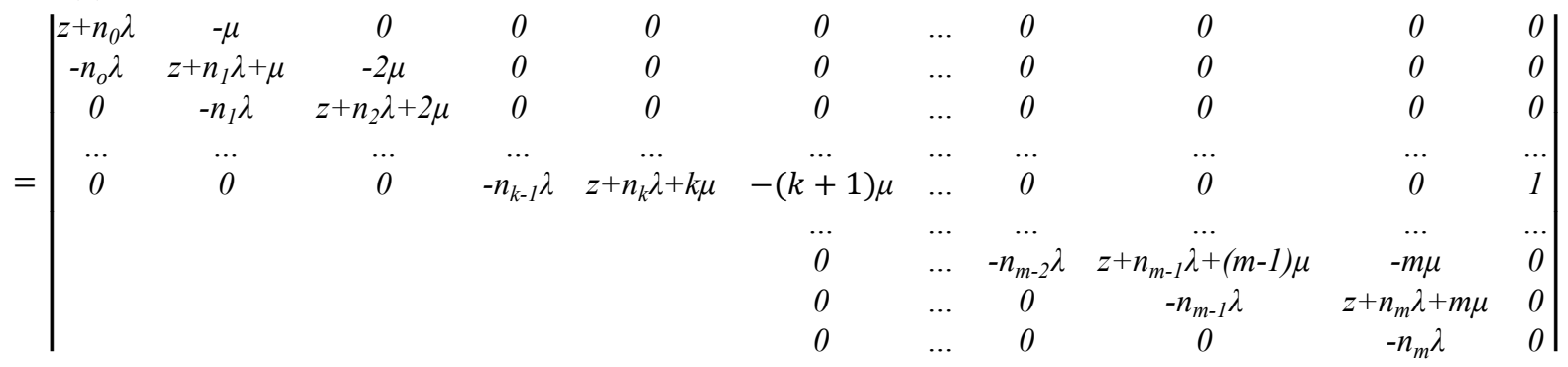

Writing the determinant (3.7) as the product of factors:

$$
\Delta(z)=z\left(z+z_{o}\right)\left(z+z_{1}\right) \ldots\left(z+z_{m}\right)
$$

where the are the roots of the equation

$$
\frac{\Delta(z)}{z}=z^{m+1}+A_{1} z+\cdots+A_{m} z+A_{m+1}=0
$$

and writing the determinant $\Delta^{(\mathrm{K})}(\mathrm{z})$ in the form of a polynomial.

$$
\lambda^{m+1-k} \pi_{i=k}^{m} n_{i}\left(B_{k}+B_{k=1} z+\cdots+B_{1} z^{k-1}+B_{0} z^{k}\right)
$$

We can get

$$
P_{m+1}^{*(k)}(z)=\lambda^{m+1-k} \prod_{i=k}^{m} n_{i}\left[\frac{B_{k}+B_{k-1} z+\cdots+B_{1} z^{k-1}+z^{k}}{z\left(z+z_{0}\right)\left(z\left(z+z_{1}\right) \ldots\left(z+z_{m}\right)\right.}\right]
$$

This expression corresponds to the original

$$
P_{m+1}^{*(k)}(T)=\lambda^{m+1-k} \quad \begin{gathered}
m \\
i=k \\
i=k
\end{gathered}\left[\frac{B_{k}}{\pi_{i=k^{z} j}^{m}}-\sum_{s=0}^{m}\left\{\begin{array}{c}
\sum_{j=0}^{k} B_{k-j}\left(z_{s}\right)^{j} e^{-z s^{t}} \\
\begin{array}{cc}
Z_{s} \pi_{q=0}^{m}\left(Z_{q}-Z_{s}\right) \\
q \neq s
\end{array}
\end{array}\right\}\right]
$$

where: $\mathrm{B}_{0}=1$.

In order to obtain all the roots of $Z_{i}$, let us solve equation (3.10) of degree $(m+1)$. The coefficients $B_{k}, B_{k-1}, \ldots B_{1}$ can be found from the expression.

$$
\begin{aligned}
& \frac{\Delta^{(\mathrm{k})}(\mathrm{z})}{\lambda^{\mathrm{m}+1-\mathrm{k} \mathrm{i}_{\mathrm{i}=1}^{\mathrm{m}} \mathrm{n}_{\mathrm{i}}}} \\
& \left|\begin{array}{ccccccc}
\mathrm{z}+\mathrm{n}_{0} \lambda & -\mu & 0 & \ldots & 0 & 0 & 0 \\
-\mathrm{n}_{0} \lambda & \mathrm{z}+\mathrm{n}_{1} \lambda+\mu & -2 \mu & \ldots & 0 & 0 & 0 \\
0 & -\mathrm{n}_{1} \lambda & \mathrm{z}+\mathrm{n}_{1} \lambda+2 \mu & \ldots & 0 & 0 & 0 \\
\ldots & \ldots & \ldots & \ldots & \ldots & \ldots & \ldots \\
0 & 0 & 0 & \ldots & -\mathrm{n}_{\mathrm{k}-2} \lambda & \mathrm{z}+\mathrm{n}_{\mathrm{k}-2} \lambda+(\mathrm{k}-2) \mathrm{u} & -(\mathrm{k}-1) \mu \\
0 & 0 & 0 & \ldots & 0 & -\mathrm{n}_{\mathrm{k}-2} \lambda & \mathrm{z}+\mathrm{n}_{\mathrm{k}-2} \lambda+(\mathrm{K}-1) \mu
\end{array}\right|
\end{aligned}
$$

It can be shown that the coefficient $\mathrm{Bk}$ is equal to the product. 


$$
B_{k}=\lambda^{k} \begin{gathered}
k-1 \\
\pi n_{i} \\
i=0
\end{gathered}
$$

which when inserted into the first term of expression (3.13), will give

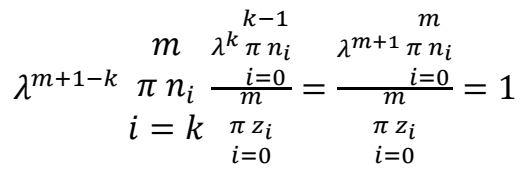

because the free term $A_{m+1}$ of the algebraic equation (3.10) is present in the numerator and the denominator of (3.16).

Taking account of equality (3.16), a formula can be found from (3.13) for the probability of unfailing operation of the system with a repairable standby, which is true for the initial conditions (3.5):

$$
R^{(k)}(T)=1-P_{m+1}^{(K)}(T)=\lambda^{m+1-k} \pi_{i=k}^{m} n_{i}\left[\sum_{s=0}^{m}\left\{\frac{\sum_{j=0}^{k} B_{k-j}\left(-z_{s}\right)^{j}}{z_{s} \pi_{\substack{q \\ q=0 \\ q \neq \neq}}\left(z_{q}-z_{S}\right)} e^{-Z_{S} T}\right\}\right]
$$

Expression (3.17) is the most common formula. Let us now discuss the case when all the elements are in good order at the initial moment $\mathrm{T}=0$, i. e,

$$
P_{0}(0)=1 ; P_{i}(0)=0 \text { with } i \neq 0
$$

in this case

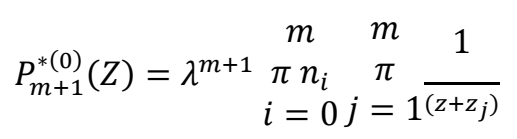

Where $\mathrm{Z}_{-1}=0$.

Setting $\mathrm{k}=0$ in (3.17) and nothing that in this case $\mathrm{B}_{0}=1$ and the other $\mathrm{B} i$ values are equal to zero, we get

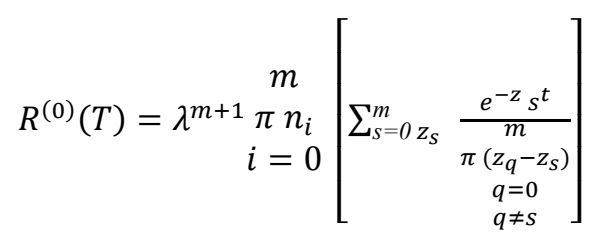

If the reliability $\mathrm{R}^{(\mathrm{k})}(\mathrm{T})$ of standby intended for prolonged use is known, it is always possible to determine also the mean life time of the system,

$$
M=\int_{0}^{\infty} R^{(k)}(T) d T
$$

since formula (3.17) for $\mathrm{R}^{(\mathrm{k})}(\mathrm{T})$ comprises the of $\mathrm{m}+1$ exponential terms of the form $\mathrm{D}_{\mathrm{i}} \exp \left\{-\mathrm{z}_{\mathrm{i}} \mathrm{T}\right\}$,

where $D_{i}=\frac{a_{i}}{z_{i}}$,

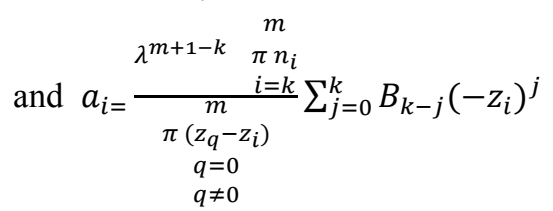

The $z_{i}$ are the roots of the characteristic equation (3.10).

The mean life time of the system in concern is equal to

$$
\mathrm{M}=\sum_{\mathrm{i}=1}^{\mathrm{m}+1} \frac{\mathrm{D}_{\mathrm{i}}}{\mathrm{Z}_{\mathrm{i}}}
$$

\section{Special Case of Two Main Units and Two Standby Redundant Units}

Let us now consider several quantitative examples for a system composed of two operating $(\mathrm{N}=2)$ and two standby $(\mathrm{m}=2)$ units. Let the parameters of the units be equal to

$\lambda=0.11 / \mathrm{h} ; \mu=11 / \mathrm{h} ; \rho=0.1$

We find $\mathrm{R}(\mathrm{T})$ and $\mathrm{M}$ for various cases: 


\subsection{Lightly Loaded Standby}

a- Only two operating units are in good order at the initial moment, and two standby units can be renewed in the process of functioning of the system. The standby units will be in relieved operating conditions with a coefficient $r=0.05$. In this case we have in conformity with formula (2.2) $\leq n_{0}=3, \mathrm{n}_{1}=2.5, \mathrm{n}_{2}=2$. The determinant (3.7). will be equal to

$$
\Delta(z)=\left|\begin{array}{cccc}
z+n_{0} \lambda & -\mu & 0 & 0 \\
-n_{0} \lambda & z+n_{1 \lambda}+\mu & 0 & 0 \\
0 & -n_{1 \lambda} & z+n_{2 \lambda}+2 \mu & 0 \\
0 & 0 & -n_{2 \lambda} & z
\end{array}\right|
$$

$=Z\left(Z^{3}+3.757 Z^{2}+2.98 Z+0.015\right)$

Solving the cubic equation

$$
\frac{\Delta(Z)}{Z} Z^{3}+3.75 z^{2}+2.98 Z+0.015=0
$$

We obtain the following values for the roots:

$Z_{0}=-2.610845, Z_{1}=0.005005, Z_{2}=-1.13415$

The determinant (3.14) will be equal to

$$
\frac{\Delta^{(2)}(Z)}{\lambda n_{2}}=\frac{\Delta^{(2)}(Z)}{0.2}=\left|\begin{array}{cc}
Z+n_{0} \lambda & -\mu \\
-n_{0} \lambda & z+n_{1} \lambda+\mu
\end{array}\right|=z^{2}+1.55 z+0.075
$$

It can be seen that $B_{k}=\mathrm{B}_{2}=0.075$ and $\mathrm{B}_{\mathrm{k}-1}=\mathrm{B}_{1}=1.55$. and Now we use formula (3.17) and find

$$
\begin{aligned}
& \mathrm{R}^{(2)}(\mathrm{T}) \\
& =\lambda \cdot \mathrm{n}_{2}\left[\frac{\mathrm{B}_{2}+\mathrm{B}_{1}\left(-\mathrm{z}_{0}\right)+\left(-\mathrm{z}_{0}\right)^{2}}{\mathrm{z}_{0}\left(\mathrm{z}_{1}-\mathrm{z}_{0}\right)\left(\mathrm{z}_{2}-\mathrm{z}_{0}\right)} \mathrm{e}^{-\mathrm{z}_{0} \mathrm{~T}}+\frac{\mathrm{B}_{2}+\mathrm{B}_{1}\left(-\mathrm{z}_{1}\right)+\left(-\mathrm{z}_{1}\right)^{2}}{\mathrm{z}_{1}\left(\mathrm{z}_{0}-\mathrm{z}_{1}\right)\left(\mathrm{z}_{2-} \mathrm{z}_{1}\right)} \mathrm{e}^{-\mathrm{z}_{1} \mathrm{~T}}+\frac{\mathrm{B}_{2}+\mathrm{B}_{1}\left(-\mathrm{z}_{2}\right)+\left(-\mathrm{z}_{2}\right)^{2}}{\mathrm{z}_{2}\left(\mathrm{z}_{0}-\mathrm{z}_{2}\right)\left(\mathrm{z}_{1-}-\mathrm{z}_{2}\right)} \mathrm{e}^{-\mathrm{z}_{2} \mathrm{~T}}\right] \\
\approx & 0.0564 e^{-2.610845 T}+0.914 e^{-0.005005 T}+0.0419 e^{-1.13415 T}
\end{aligned}
$$

Moduli of the roots $Z_{i}$ are substituted into formula (3.17) because the signs have been taken into account during its derivation.

We obtain from formula (3.22)

$$
\mathrm{M} \approx 183 h .
$$

b- Let us consider the previous case (case a) with the initial conditions $\mathrm{P}_{1}(0)=1 \mathrm{P}_{i}(0)=0$, i.e. , i. e., when only one standby unit is faulty at the initial moment $T=0$. In this case the determinant (3.14) is equal to

$$
\frac{\Delta^{(1)}(z)}{\lambda^{2} n_{1} n_{2}}=\frac{\Delta^{(1)}(z)}{0.05}=\left|z+n_{0} \lambda\right|=0.3+z
$$

Suppose, we obtain, $B_{k}=B_{1}=0.3$ and $B_{k-1}=B_{0}=1$ from formula (3.17)

$$
\begin{aligned}
& R^{(1)}(T)=\lambda^{2} n_{1} n_{2}\left[\frac{B_{1}-Z_{0}}{Z_{0}\left(Z_{1}-Z_{0}\right)\left(Z_{2}-Z_{0}\right)} e^{-Z_{0} T}+\frac{B_{1}-Z_{1}}{Z_{1}\left(Z_{0}-Z_{1}\right)\left(Z_{2}-Z_{1}\right)} e^{-Z_{1} T}+\frac{B_{1}-Z_{2}}{Z_{2}\left(Z_{0}-Z_{2}\right)\left(Z_{1}-Z_{2}\right)} e^{-Z_{2} T}\right] \\
& \approx-0.0115 \mathrm{e}^{-2.610845 \mathrm{~T}}+\mathrm{e}^{-0.005005 \mathrm{~T}}+0.022 \mathrm{e}^{-1.13415 \mathrm{~T}} .
\end{aligned}
$$

From formula (3.22)

Moduli of the roots $Z_{i}$ are substituted into formula (3.17) because the signs have been taken into account during its derivation.

We obtain from formula (3.22)

$$
\mathrm{M}=200 h
$$

c- Let us consider the case (a) with the initial conditions $\mathrm{P}_{0}(0)=1, \mathrm{P}_{i}(0)=0$, i.e., when all units are operable at the initial moment $T=0$. We find from formula (3.20) that

$$
\begin{gathered}
R^{(0)}(T)=\lambda^{3} n_{0} n_{1} n_{2}\left[\frac{1}{Z_{0}\left(Z_{1}-Z_{0}\right)\left(Z_{2}-Z_{0}\right)} e^{-Z_{0} T}+\frac{1}{Z_{1}\left(Z_{0}-Z_{1}\right)\left(Z_{2}-Z_{1}\right)} e^{-Z_{1} T}\right. \\
\left.+\frac{1}{Z_{2}\left(Z_{0}-Z_{2}\right)\left(Z_{1}-Z_{2}\right)} e^{-Z_{2} T}\right] \\
\approx 0.0015 \mathrm{e}^{-2.610845 \mathrm{~T}}+1.0182 \mathrm{e}^{-0.005005 \mathrm{~T}}-0.0079 \mathrm{e}^{-1.13415 \mathrm{~T}} .
\end{gathered}
$$


Whence $\mathrm{M} \approx 203.5 h$.

\subsection{Loaded Standby}

Let us consider case (a) but with a loaded stand by $(r=1)$ and in the absence of queuing for renewal. From formula (2.2) we have $\mathrm{n}_{0}=4, \mathrm{n} 1=3, \mathrm{n} 2=2$. The determinant (3.7) is equal to

$$
\Delta(z)=z\left(z^{3}+3.95 z^{2}+3.26 z+0.024\right)
$$

Hence $Z_{0}=-26877, Z_{1}=-0.0075, Z_{2}=-1.21$.

From formula (3.20) we obtain

$$
\mathrm{R}^{(0)}(T)=0.0009 e^{-2.5229 T}+0.989 e^{-0.003 T}-0.0048 e^{-1.0736 T}
$$

And therefore $\mathrm{M} \approx 329 \mathrm{~h}$.

4.3 Non-loaded Standby

Let us consider the same system but with an unloaded

Standby $(r=0)$. We have $\mathrm{n}_{0}=\mathrm{n}_{1}=\mathrm{n}_{2}=\mathrm{m}=2$.further

$$
\Delta(z)=z\left(z^{3}+3.6 z^{2}+2.727 z+0.008\right)
$$

$Z_{0}=-2.5229 \mathrm{~m} Z_{1}=0.003, Z_{2}=-1.0736$

$$
\mathrm{R}^{(0)}(T)=0.0009 e^{-2.5229 T}+0.989 e^{-0.003 T}-0.0048 e^{-1.0736 T}
$$

where $\mathrm{M} \approx 329 \mathrm{~h}$

\section{Conclusion}

The mathematical methods of calculating the reliability of renewable systems based on the use of Markov's random processes. The availability, the reliability and the mean life time of non-redundant and different standby redundant systems with renewal are obtained.

Then we conclusion that renewal together with standby is an effective means of increasing the reliability of a system. In the above cases the mean Life time of the system is equal to:

$M=132 \mathrm{~h}$ with renewal and loaded standby;

$M=183 \mathrm{~h}$ with renewal and lightly loaded standby;

$M=329 \mathrm{~h}$ with renewal and unloaded standby;

i.e., the mean life time appreciably increases with standby and renewal.

\section{Refrences}

Dhillon B.S., \& R.B. Mishra. (1984). Reliability evaluation of system with critical human error. Microelectron. Reliab, 24(1), 743-759, $\quad$ Retrieved from https://www.sciencedirect.com/science/article/abs/pii/0026271484902221. https://doi.org/10.1016/0026-2714(84)90222-1

Mokaddis, G.S., Ayed Y.M., \& Al-Hajeri, H.S. (2013). Probabilistic analysis of two warm standby system with instructions at need. African Journal of Computer Science Research, 6(2), 20-25. Retrieved from https://academicjournals.org/journal/AJMCSR/article-abstract/6E6BF316108.

Mokaddis, G.S., G.S. Khalil, \& Hanaa Alhajri. (2016). Reliability Analysis of a two Dissimilar Unit Warm Standby Redundant System with Imperfect Switch. International Journal of Modern Engineering Research (IJMER), 6(8), versiob 1, 9652. August 2016, Retrieved from http://www.ijmer.com/papers/Vol6_Issue8/Version-1/G6815269.pdf.

Mokaddis, G.S., Tawfek, M.L., El-Hssia, \& S.A.M. (1996). Reliability analysis of man machine system operating subject to physical conditions. Puplished in "Microelectronics and Reliability", England.

Ryabinin, L. (1976). Reliability of Engineering Systems Principles and Analysis. Mir., Pub. Moscow. Retrieved from https://books.google.com.kw/books/about/Reliability_of_Engineering_Systems.html?id=QSWiPgAACAAJ \&rediresc $=\mathrm{y}$.

Samuel Karllin. Afirst course in stochastic processes. New York and London http://www.gbv.de/dms/hebis-mainz/toc/185095224.pdf. 
Tawfeek M. L. (2006). Reliability evaluation of electric power systems in alternating environment. JOUR. Inst. Maths. \& Computer Sciences, 17(2), 193-204.

Univ S.V., \& Kurnol. (1994). Availability and frequency measures of a non-identical two component system in the presence of common cause shock failures. Management Sciences, 34(1), 147-151. Retrieved from https://www.sciencedirect.com/science/article/abs/pii/0026271494904847?via\%3Dihub.

https://doi.org/10.1016/0026-2714(94)90484-7

\section{Copyrights}

Copyright for this article is retained by the author(s), with first publication rights granted to the journal.

This is an open-access article distributed under the terms and conditions of the Creative Commons Attribution license (http://creativecommons.org/licenses/by/3.0/). 